\title{
Review
}

\section{Murine coronavirus neuropathogenesis: determinants of virulence}

\author{
Timothy J Cowley and Susan R Weiss \\ Department of Microbiology, University of Pennsylvania School of Medicine, Philadelphia, Pennsylvania, USA
}

\begin{abstract}
Murine coronavirus, mouse hepatitis virus (MHV), causes various diseases depending on the strain and route of inoculation. Both the JHM and A59 strains, when inoculated intracranially or intranasally, are neurovirulent. Comparison of the highly virulent JHM isolate, JHM.SD, with less virulent JHM isolates and with A59 has been used to determine the mechanisms and genes responsible for high neuropathogenicity of MHV. The focus of this review is on the contributions of viral spread, replication, and innate and adaptive immunity to MHV neuropathogenesis. JHM.SD spreads more quickly among neurons than less neurovirulent MHVs, and is able to spread in the absence of the canonical MHV receptor, CEACAM1a. The observation that JHM.SD infects more cells and expresses more antigen, but produces less infectious virus per cell than A59, implies that efficient replication is not always a correlate of high neurovirulence. This is likely due to the unstable nature of the JHM.SD spike protein (S). JHM.SD induces a generally protective innate immune response; however, the strong neutrophil response may be more pathogenic than protective. In addition, JHM.SD induces only a minimal T-cell response, whereas the strong T-cell response and the concomitant interferon- $\gamma($ IFN $-\gamma)$ induced by the less neurovirulent $\mathrm{A59}$ is protective. Differences in the $\mathrm{S}$ and nucleocapsid (N) proteins between A59 and JHM.SD contribute to JHM.SD neuropathogenicity. The hemmagglutinin-esterase (HE) protein may enhance neuropathogenicity of some MHV isolates, but is unlikely a major contributor to the high neuroviruence of JHM.SD. Further data suggest that neither the internal (I) protein nor nonstructural proteins ns4, and ns2 are significant contributors to neurovirulence. Journal of NeuroVirology (2010) 16, 427-434.
\end{abstract}

Keywords: JHM and A59 strains; mouse hepatitis virus; neurovirulence, viral spread

\section{Background}

Murine coronavirus, mouse hepatitis virus (MHV), is a large, enveloped, single-stranded, positive-sense RNA virus (Figure 1). MHV can cause a wide range of illness depending on the strain and the route of infection; these include respiratory, gastrointestinal, hepatic, and central nervous system (CNS) diseases.

Address correspondence to Susan R. Weiss, Department of Microbiology, University of Pennsylvania School of Medicine, 36th Street and Hamilton Walk, Philadelphia, PA 19104-6076, USA. E-mail: weisssr@mail.med.upenn.edu

This work was supported by NIH grants NS-54695 and AI-60021 to S.R.W. T.J.C. was partially supported in part by NIH training grant AI-07324.

Received 1 September 2010; revised 22 September 2010; accepted 24 September 2010.
These infections provide models for the study of encephalitis and demyelinating diseases such as multiple sclerosis (MS), hepatitis (Bender and Weiss, 2010; Weiss and Navas-Martin, 2005), and severe acute respiratory syndrome (SARS) (De Albuquerque et al, 2006).

Neurotropic strains of MHV cause disease in the CNS when inoculated intracranially or intranasally. Virus generally does not reach the brain of immunocompetent mice if inoculated intrahepatically or intraperitoneally. After intranasal inoculation, the virus travels transneuronally up the olfactory nerves to the olfactory bulbs where it spreads into the brain parenchyma and eventually into the spinal cord (Barnett and Perlman, 1993; Perlman et al, 1989, 1995; Sun and Perlman, 1995). MHV is thought to also spread through the cerebrospinal fluid, following intracranial inoculation (Wang et al, 1992). CNS 


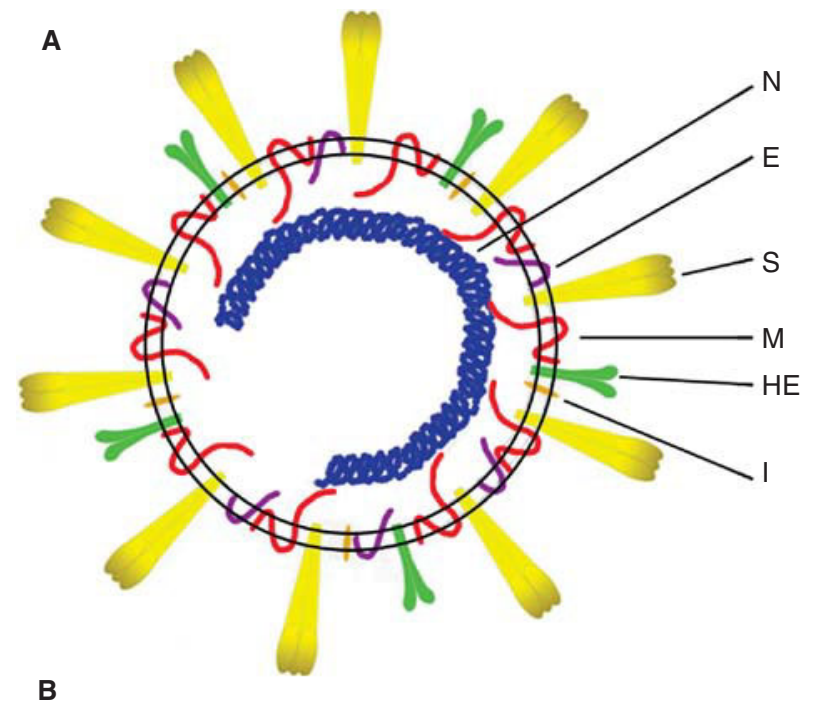

B

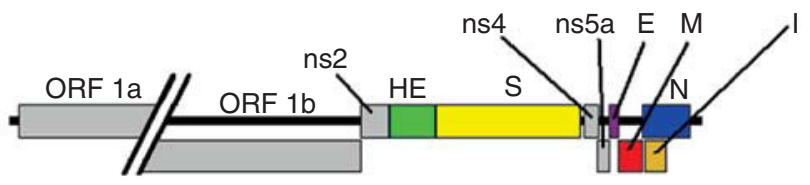

Figure 1 Schematic representation of the MHV virion and genome. (A) The MHV virion contains a helical nucleocapsid consisting of nucleocapsid protein $(\mathrm{N})$ bound to a positivesense RNA genome. The viral envelope contains spike peplomers $(S)$, small envelope protein (E), and membrane protein (M). Depending on the viral strain, the viral envelope may also contain hemagglutinin-esterase protein (HE) and the internal protein (I). (B) MHV genome. The position of MHV genes are shown along with the relative sizes, except for ORF1a and ORF1b, which are truncated in the diagram (represented by hash marks). Note that that there will be some variation by strain.

infection leads to viremia and spread of virus to other susceptible organs such as the liver (Lavi et al, 1986, 1988).

Two neurotropic strains that are commonly studied are A59 and JHM. A59 is a tissue culture-adapted dualtropic strain that infects the liver as well as the brain. A59 causes moderate to severe hepatitis and in the brain, mild encephalitis and demyelination (Lavi et al, 1984; Phillips et al, 1999); MHV-induced demyelination provides a model for multiple sclerosis. Infectious A59 is generally cleared by 10 days post intracranial inoculation, after which mice develop demyelination peaking at 3 to 4 weeks post infection (Houtman and Fleming, 1996b; Matthews et al, 2001; Sutherland et al, 1997). JHM was isolated from a paralyzed mouse (Cheever et al, 1949) and subsequently serially passaged in mouse brains, after which various clones were isolated. The use of multiple JHM clones, with different levels of neurovirulence, by various laboratories has necessitated the use of additional nomenclature to distinguish among these isolates. JHM.SD (formerly designated as MHV-4) (Ontiveros et al, 2003), the focus of this review, is among the most neurovirulent isolates
(Fazakerley et al, 1992; Gallagher et al, 1990), causing lethal encephalitis. An intracranial inoculation with only a few plaque-forming units (PFU) of JHM.SD kills nearly all the infected mice within about 1 week. Like A59, JHM induces demyelinating disease in the surviving mice (Lampert et al, 1973; Perlman et al, 1987; Weiner, 1973).

Because A59 and JHM.SD display vastly different levels of neurovirulence, we have used them to investigate the viral determinants of high MHVinduced neuropathogenesis. JHM.SD has a 50\% lethal dose $\left(\mathrm{LD}_{50}\right)$ of less than $10 \mathrm{PFU}$ after intracranial inoculation of 4-week-old C57BL/6 (B6) mice, whereas A59 is approximately 1000-fold less virulent, with a $\mathrm{LD}_{50}$ of 3000 to $5000 \mathrm{PFU}$ (Iacono et al, 2006; MacNamara et al, 2005). Both A59 and JHM.SD infect all major CNS cell types, including neurons, astrocytes, and microglia; viral antigen is found throughout the brain after infection with either virus, but JHM.SD produces more widespread infection, with larger foci of viral antigen expression (Fishman et al. 1985; Lavi et al, 1988; Matsubara et al, 1991; Parham et al, 1986).

Several factors contribute to enhanced lethality of highly encephalitic JHM isolates, such as JHM.SD. These include spread, replication, and adaptive and innate immunity. The kinetics of viral replication and antigen expression as well as host response are diagrammed in Figure 2. Several viral proteins have been investigated as to their role in strain-specific differences in MHV neurovirulence. A diagram of the MHV virion with structural proteins indicated as well as a schematic showing the locations of genes encoding both structural and nonstructural viral proteins is shown in Figure 1.

The expression of either the spike or nucleocapsid protein of JHM within the A59 background confers a decrease in $\mathrm{LD}_{50}$ to less than 10 PFU after intracranial inoculation (Cowley et al, 2010; Iacono et al, 2006; Navas and Weiss, 2003; Phillips et al, 1999). The virulence factors as well as the mechanisms by which viral proteins enhance neurovirulence are discussed below.

\section{MHV spread}

\section{Neuron-to-neuron spread}

In primary hippocampal neuronal cultures, JHM.SD spreads more extensively than A59, suggesting that there is an inherent difference in spread among neurons in the absence of host factors such as the immune response. In these in vitro cultures, both A59 and JHM.SD produce foci of infection that increase in size over time, without increasing in number; this occurs more rapidly in JHM.SDinfected cultures as compared with A59-infected cultures. JHM.SD produces very low levels of infectious virus in the medium as compared with A59 (Bender et al, 2010), suggesting that JHM.SD 
A59

A

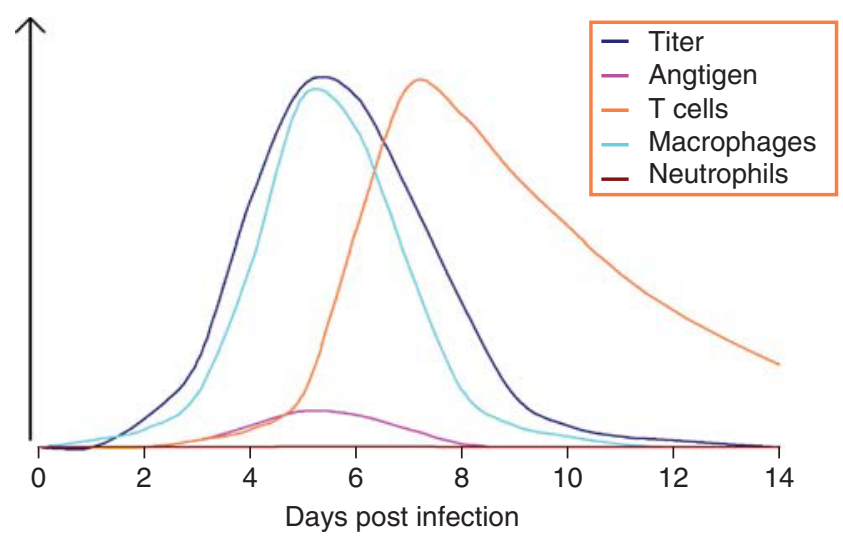

B

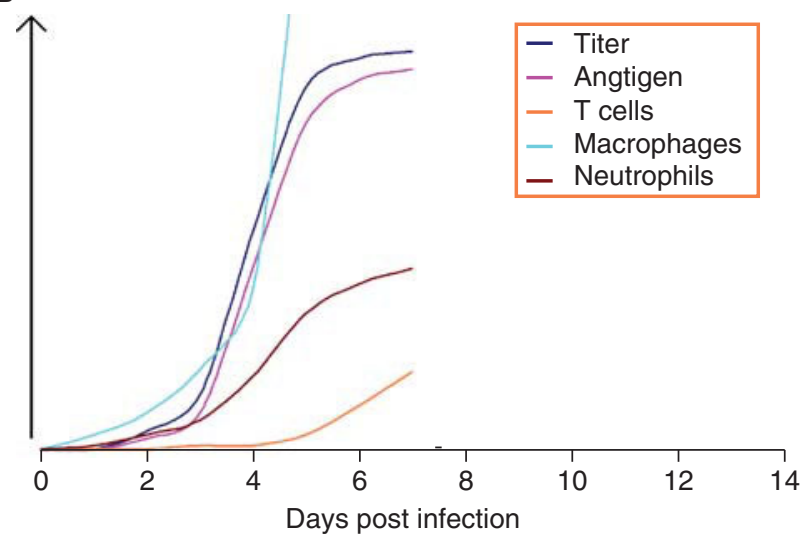

Figure 2 Diagram of parameters that correlate with neurovirulence. Shown are schematic drawings of the kinetics of replication, viral antigen, T cells, neutrophils, and macrophages in the brains of 4-week-old C57BL/6 mice infected intracranially with A59 compared with JHM.SD during the first 2 weeks of infection. Note that the graph is cropped and macrophage titers by day 7 in JHM.SD-infected mice are approximately 4 times that of A59. JHM-infected mice typically die by day 7 at a low dose (10-50 PFU) of virus.

spread is primarily neuron to neuron (Bender et al, 2010; Phillips et al, 2002). In rat hippocamapal neurons and in the neuronal cell line OBL-21, a JHM isolate used by S. Dales et al was observed to move transneuronaly in a primarily retrograde movement with some anterograde movement as well (Pasick et al, 1994).

The availability of reverse genetics systems has promoted the mapping of pathogenic properties to viral genes. Analysis of A59/JHM chimeric viruses demonstrated that the spike protein is largely responsible for the rapid spread of JHM. Replacement of the spike gene of A59 with that of JHM (rA59/S JHM $_{\text {) }}$ confers increased spread in the brain and in primary hippocampal neurons, and conversely replacement of the JHM spike gene with that of A59 (rJHM/S $\left.\mathrm{A}_{\mathrm{A} 59}\right)$ results in reduced spread in the brain (Iacono et al, 2006; Phillips et al, 2002). Some JHM isolates with spike mutations are attenuated for encephalitis, but still induce demyelination. One such isolate, JHM2.2-V-1, was selected as an escape variant for neutralization by anti-spike monoclonal antibody J2.2. It has an $\mathrm{L} 1114 \mathrm{~F}$ amino acid substitution in the spike and is glial tropic; it fails to infect neurons, which most likely explains its attenuation for encephalitis (Wang et al, 1992). In the context of JHM/A59 chimeric viruses, the nucleocapsid protein of JHM also confers increases in the extent of viral antigen expressed in the brain; however, the mechanism is uncertain and nucleocapsid protein does not enhance neuron-to-neuron spread in primary hippocampal neuron cultures (Cowley et al, 2010).

\section{Carcinoembryonic antigen-related cell adhesion} molecule 1a (CEACAM1a) receptor-dependent and -independent spread

Another factor that contributes to high neurovirulence is the ability of some JHM variants, such as
JHM.SD and JHM cl-2 (Taguchi et al, 1985), to spread in the absence of the canonical MHV receptor, CEACAM1a. This was originally demonstrated in tissue culture (Gallagher et al, 1992; Taguchi et al, 1999) and more recently in primary hippocampal neuron cultures (Bender et al, 2010). A very small number of cells in primary neuronal cultures derived from ceacam $1 a^{-/-}$mice were infected by A59 or JHM. SD; however, A59 failed to spread beyond the initially infected neurons, whereas JHM.SD spread robustly. Furthermore, when ceacam $1 a^{-/-}$mice were inoculated with sufficiently high titers of JHM.SD, but not A59, they developed lethal CNS disease (Miura et al, 2008). Thus, the ability to spread in the absence of CEACAM1a may allow JHM.SD to spread more rapidly than A59 and/ or infect different neuronal subsets.

The expression of CEACAM1a protein by neurons has never been demonstrated. When measured by quantitative reverse transcriptase-polymerase chain reaction (qRT-PCR), expression was barely above background and may have been due to contamination of other, CEACAM1a-expressing, cell types (Bender et al, 2010). It was suggested that JHM cl-2 may first infect microglia, which had been demonstrated to express CEACAM1a (Ramakrishna et al, 2004), and then spread into neurons (Nakagaki and Taguchi, 2005). However, the observations that there are very few foci of infected ceacam $1 a^{-/-}$neurons compared to wild-type neurons and that A59 fails to spread from initially infected ceacam $1 a^{-/-}$neurons suggest that neurons express CEACAM1a, which is essential for spread of A59, but not JHM. It is not clear how either strain enters ceacam $1 a^{-/-}$neurons.

Most JHM isolates are not capable of CEACAM1aindependent spread. One such isolate, JHM.IA, like JHM.SD, is highly neurovirulent, and both viruses spread rapidly in the CNS and are uniformly fatal 
in 4- to 6-week-old mice (Haspel et al, 1978; Knobler et al, 1981; MacNamara et al, 2005; Ontiveros et al, 2001; Perlman et al, 1987). However, JHM.SD is significantly more virulent than JHM.IA when assessed in a different model system, in which suckling mice are inoculated intranasally and nursed on dams previously immunized with JHM.IA (Ontiveros et al, 2003). Thus the inability of JHM. IA to carry out CEACAM1a-independent spread may contribute to subtle differences in virulence, but the fact that JHM.IA is similarly virulent to JHM. $\mathrm{SD}$ in adult B6 mice suggests that CEACAM1aindependent spread is likely not the only reason for enhanced virulence of JHM.SD in adult mice. Furthermore, it is quite possible that CEACAM1aindependent spread is mechanistically different in primary neurons as compared with cell lines.

\section{Hemagglutinin-esterase}

The role of hemagglutinin-esterase (HE) in neurovirulence and spread has been a subject of much speculation with evidence both for and against a role for $\mathrm{HE}$ in neurovirulence (LaMonica et al, 1991; Yokomori et al, 1992, 1993, 1995). However, it was demonstrated that a recombinant A59 expressing the hemagglutinin-esterase of the MHV-S strain and the spike protein of JHM.SD was more neurovirulent than an isogenic virus that does not express HE (Kazi et al, 2005). However, abrogation of the expression of HE within a recombinant JHM.SD genome had no affect on neurovirulence (unpublished data). This implies that HE can enhance neurovirulence for some strains, but that HE either fails to modulate JHM.SD neurovirulence or the effect of HE expression during JHM infection is not detectable due to the very high neurovirulence of JHM.

\section{Replication}

Infectious viral titers in the brains of mice infected with MHV do not always correlate with the severity of the infection. When inoculated at equivalent PFU, A59 and JHM.SD replicate to similar titers in the brain, even though JHM.SD is more lethal and expresses more intracellular antigen in the CNS (Cowley et al, 2010; MacNamara et al, 2005; Phillips et al, 1999). In addition, recombinant A59 expressing the JHM.SD spike gene ( $\mathrm{rA59} / \mathrm{S}_{\mathrm{JHM}}$ ) replicates to lower final titers than A59, even though, like JHM. $\mathrm{SD}$, it has an $\mathrm{LD}_{50}$ of less than $10 \mathrm{PFU}$ and spreads more efficiently in the CNS than A59 (Phillips et al, 1999). This may be due to the unstable nature of the JHM.SD spike protein, which can lead to receptorindependent conformational changes and premature inactivation (Gallagher and Buchmeier, 2001; Krueger et al, 2001). Consistent with this, the JHM. $\mathrm{SD}$ spike is more sensitive to heat and high $\mathrm{pH}$ treatments (Tsai et al, 2003). Perhaps as a consequence, JHM.SD produces more virus particles per
PFU than A59 (unpublished data) and replicates to significantly 100- to 1000 -fold lower titers in tissue culture (Cowley et al, 2010; Phillips et al, 1999). However, titer is indicative of disease severity in some cases, when comparing two viruses expressing the same spike protein. For example, recombinant A59 expressing the JHM nucleocapsid ( $\mathrm{rA59} / \mathrm{N}_{\mathrm{IHM}}$ ) is more lethal and infects more cells in the CNS than A59, and this is associated with greater replication in the brain (Cowley et al, 2010).

\section{Innate immune response}

Infections with A59 or JHM.SD generate different cytokine/chemokine profiles. Infections with either virus induces macrophage inhibitory factor (MIF) and tumor necrosis factor- $\alpha$ (TNF- $\alpha$ ), which remain elevated throughout infection. A59 induces a strong protective interferon- $\gamma$ (IFN- $\gamma$ ) response (Rempel et al, 2004a; Scott et al. 2008). JHM.SD, on the other hand, induces a weaker IFN- $\gamma$ response (Rempel et al, 2004a; Scott et al, 2008) and there is one report of a stronger IFN- $\beta$ response early in JHM. SD infection (Rempel et al, 2004a). Additionally, JHM.SD induces more macrophage chemoattractants, such as macrophage inflammatory protein- $1 \alpha$ and $-1 \beta$ (MIP- $1 \alpha$ and MIP-1 $\beta$ ) and MIP-2, consistent with the greater number of macrophages recruited into the CNS during JHM.SD infection (Iacono et al, 2006; Rempel et al, 2004b). The robust macrophage infiltration induced by JHM.SD partially maps to the JHM.SD spike gene, as evidenced by the greater level of macrophage recruitment in the CNS of rA59/S $\mathrm{S}_{\mathrm{HHM}}$-infected mice as compared with A59-infected animals (Rempel et al. 2004b; Scott et al, 2008).

Shortly after MHV infection, neutrophils traffic to the brain and release matrix metalloproteinases (MMPs). The combination of cytokines and MMPs causes disruption of the blood-brain barrier, which facilitates the entry of mononuclear cells (Zhou et al, 2002). JHM.SD infection leads to the recruitment of greater numbers of neutrophils than A59 infection, likely a result of the increased level of MIP-2 during JHM infection (Iacono et al, 2006; Rempel et al, 2004a; Scott et al, 2008). Depletion of neutrorophils during infection with the more attenuated DM variant of JHM resulted in a reduction in inflammatory cell infiltration, increased viral replication, and increased lethality, leading to the conclusion that neutrophils were protective against MHV infection (Zhou et al, 2003). However, although neutrophils are important in early control of virus, they can be pathogenic in generating toxic reactive oxygen species. Indeed, the greater recruitment of neutrophils during JHM.SD infection compared to A59 was demonstrated to be more destructive than protective (Iacono et al, 2006). Natural killer cells also enter the brain early in infection. They secrete IFN- $\gamma$, 
which may assist in clearing virus early in infection before the adaptive immune response develops (Iacono et al, 2006; Rempel et al, 2004a).

\section{Adaptive immune response}

The adaptive immune response, both $\mathrm{B}$ cell and $\mathrm{T}$ cell, is important in restricting MHV infection. B cell-deficient mice can clear virus with normal kinetics, but in the absence of neutralizing antibodies, virus reappears in the CNS, but not the liver, about 2 weeks post infection (Lin et al, 1999; Matthews et al, 2001). SCID (severe combined immunodeficiency) and nude mice fail to clear virus, indicating that $\mathrm{T}$ cells are important for clearance (Fazakerley et al, 1992; Houtman and Fleming, 1996a). CD8 $\mathrm{T}$ cells are primarily responsible for viral clearance, whereas CD4 $\mathrm{T}$ cells are required for CD8 T-cell recruitment and maintenance (Stohlman et al, 1998). Adoptive transfer of CD4 T cells alone does not restrict virus replication, but depletion of CD4 T cells prevents CD8 T cell-mediated protection (Sussman et al, 1989). Consistent with the role for CD8 $\mathrm{T}$ cells in viral clearance, $\beta_{2}$-microglobulin-deficient mice, which are deficient in major histocompatibility complex (MHC) class I expression, are significantly more susceptible to A59 infection (Gombold et al, 1995).

Viral strain-dependent differences in T-cell response make significant contributions to virulence. JHM.SD induces a weak T-cell response, whereas the less virulent JHM 2.2-V-1 and A59 induce robust responses (Iacono et al, 2006; Marten et al, 2003; Rempel et al, 2004a). Quantification of virus specific $\mathrm{T}$ cells after JHM 2.2-V-1 infection showed that priming and the initiation of T-cell expansion occurs in the cervical lymph nodes (CLNs). Dendritic cells (DCs) carrying virus or viral antigen migrate from the brain to the CLNs where antigen-specific T-cell priming is believed to occur (Dorries, 2001; Stevenson et al, 1997); treatment of DCs with pertussis toxin prevents them from migrating from the CLNs and, in turn, prevents T-cell trafficking into the brain (Karman et al, 2004). After initial expansion in the CLNs, $\mathrm{T}$ cells expand further in the spleen before trafficking to the brain (Marten et al, 2003). Infectious JHM.SD is barely detectable in CLNs, whereas A59 viral titers are much higher (Macnamara et al, 2008). The induction of a robust $\mathrm{T}$-cell response does not map to spike, as rA59/S $\mathrm{S}_{\mathrm{HM}}$ induces a strong $\mathrm{T}$-cell response and infectious viral titers similar to A59 are detected in CLNs (Cowley et al, 2010; Iacono et al, 2006; Macnamara et al, 2008; Rempel et al, 2004b). The cytolytic activity as well as the production of IFN- $\gamma$ by CD8 T cells are crucial for the ability to clear infection from the CNS (Marten et al, 2001; Parra et al, 1999). Whereas perforin is important for clearance from astrocytes (Lin et al, 1997; Parra et al, 2001), IFN- $\gamma$ facilitates cytolytic killing by up-regulating MHC expression on infected cells and mediates clearance from oligodendrocytes (Bergmann et al, 2003; Parra et al, 1999). The mechanism of viral clearance from neurons is not yet known.

\section{Role of viral proteins in neuropathogenesis}

As discussed above, spike and nucleocapsid proteins have been implicated in strain differences in virulence. Several other MHV proteins have been investigated as candidate virulence determinants. Two MHV nonstructural proteins, ns2 and ns5a, have been implicated in type I interferon antagonism (Koetzner et al, 2010; Zhao and Weiss, unpublished data). ns2 is predicted to have cyclic phosphodiesterase (CDP) activity. Mutations in either of two predicted catalytic histidines of ns2 of A59 confer the loss of the ability to replicate in the liver, but have no affect on neurovirulence or in vitro replication (Roth-Cross et al, 2009). Similarly, a deletion of the ns2 gene of JHM had no affect on replication in vitro (Schwarz et al, 1990), and had no detectable effect on virulence after intracranial inoculation (personal communication, J. Leibowitz and S. Perlman). These data suggest that either the ability to resist interferon signaling is not as important in the CNS as in the liver or that resistance to interferon signaling by MHV is mediated through a different mechanism in the CNS. ns5a, like ns2, is nonessential for replication in vitro (Yokomori and Lai, 1991), but its role in neurovirulence has not been reported.

There are data indicating that the adenosine diphosphate ribose phosphatase (ADRP; X or macro) domain of nsp3 (encoded by opening reading frame 1a [ORF1a]) (Gorbalenya et al, 1991; Putics et al, 2005, 2006), internal protein, and ns4 are not likely to be important to the neurovirulence of JHM or A59. Mutation of the predicted catalytic residue in the ADRP domain of nsp3 of A59 does not alter the ability of virus to replicate in vitro or the CNS (unpublished data); however, interestingly, such mutations confer reduced replication in the liver (Eriksson et al, 2008). Abrogation of the internal protein (I) expression in the A59 genome had no affect on replication in the CNS (Fischer et al, 1997) or lethality after intracranial inoculation (unpublished data), and JHM ablated for ns4 expression was similar in lethality and CNS replication as wild-type virus (Ontiveros et al, 2001).

\section{Conclusion}

There is still much to learn about the mechanisms responsible for the high neurovirulence of JHM.SD. These include defining the roles, if any, that the envelope proteins, membrane (M) and small membrane (E), play in neurovirulence, and determining the possible impact of the many nonstructural 
proteins encoded in the replicase locus and the role of ns5a in neurovirulence. In addition, it is not fully understood how viral strain differences in the innate immune response may affect pathogenesis. It is also not well understood why JHM.SD fails to spread to and/or replicate in the CLNs, and whether this is responsible for the weak T-cell response to JHM.SD

\section{References}

Barnett EM, Perlman S (1993). The olfactory nerve and not the trigeminal nerve is the major site of CNS entry for mouse hepatitis virus, strain JHM. Virology 194: 185-191.

Bender SJ, Phillips JM, Scott EP, Weiss SR (2010). Murine coronavirus receptors are differentially expressed in the central nervous system and play virus strain-dependent roles in neuronal spread. J Virol 84: 11030-11044.

Bender SJ, Weiss SR (2010). Pathogenesis of murine coronavirus in the central nervous system. J Neuroimmune Pharmacol 5: 336-354.

Bergmann CC, Parra B, Hinton DR, Chandran R, Morrison M, Stohlman SA (2003). Perforin-mediated effector function within the central nervous system requires IFN-gamma-mediated MHC up-regulation. J Immunol 170: 3204-3213.

Cheever FS, Daniels JB, Pappenheimer AM, Baily OT (1949). A murine virus (JHM) causing disseminated encephalomyelitis with extensive destruction of myelin. I. Isolation and biological properties of the virus. J ExpMed 90: 181-194.

Cowley TJ, Long SY, Weiss SR (2010). The murine coronavirus nucleocapsid gene is a determinant of virulence. J Virol 84: 1752-1763.

De Albuquerque N, Baig E, Ma X, Zhang J, He W, Rowe A, Habal M, Liu M, Shalev I, Downey GP, Gorczynski R, Butany J, Leibowitz J, Weiss SR, McGilvray ID, Phillips MJ, Fish EN, Levy GA (2006). Murine hepatitis virus strain 1 produces a clinically relevant model of severe acute respiratory syndrome in A/J mice. J Virol 80: 10382-10394.

Dorries R (2001). The role of T-cell-mediated mechanisms in virus infections of the nervous system. Curr Top Microbiol Immunol 253: 219-245.

Eriksson KK, Cervantes-Barragan L, Ludewig B, Thiel V (2008). Mouse hepatitis virus liver pathology is dependent on ADP-ribose-1'-phosphatase, a viral function conserved in the alpha-like supergroup. J Virol 82: 12325-12334.

Fazakerley JK, Parker SE, Bloom F, Buchmeier MJ (1992). The V5A13.1 envelope glycoprotein deletion mutant of mouse hepatitis virus type- 4 is neuroattenuated by its reduced rate of spread in the central nervous system. Virol 187: 178-188.

Fischer F, Peng D, Hingley ST, Weiss SR, Masters PS (1997). The internal open reading frame within the nucleocapsid gene of mouse hepatitis virus encodes a infection of the CNS and the ensuing high neurovirulence.

Declaration of interest: The authors report no conflicts of interest. The authors alone are responsible for the content and writing of the paper.

structural protein that is not essential for viral replication. J Virol 71: 996-1003.

Fishman PS, Gass JS, Swoveland PT, Lavi E, Highkin MK, Weiss SR (1985). Infection of the basal ganglia by a murine coronavirus. Science 229: 877-879.

Gallagher TM, Buchmeier MJ (2001). Coronavirus spike proteins in viral entry and pathogenesis. Virology 279: 371-374.

Gallagher TM, Buchmeier MJ, Perlman S (1992). Cell receptor-independent infection by a neurotropic murine coronavirus. Virology 191: 517-522.

Gallagher TM, Parker SE, Buchmeier MJ (1990). Neutralization-resistant variants of a neurotropic coronavirus are generated by deletions within the amino-terminal half of the spike glycoprotein. J Virol 64: 731-741.

Gombold JL, Sutherland RM, Lavi E, Paterson Y, Weiss SR (1995). Mouse hepatitis virus A59-induced demyelination can occur in the absence of CD8+ T cells. Microb Pathog 18: 211-221.

Gorbalenya AE, Koonin EV, Lai MM (1991). Putative papain-related thiol proteases of positive-strand RNA viruses. Identification of rubi- and aphthovirus proteases and delineation of a novel conserved domain associated with proteases of rubi-, alpha- and coronaviruses. FEBS Lett 288: 201-205.

Haspel MV, Lampert PW, Oldstone MB (1978). Temperature-sensitive mutants of mouse hepatitis virus produce a high incidence of demyelination. Proc Natl Acad Sci U S A 75: 4033-4036.

Houtman JJ, Fleming JO (1996a). Dissociation of demyelination and viral clearance in congenitally immunodeficient mice infected with murine coronavirus JHM. J NeuroVirol 2: 101-110.

Houtman JJ, Fleming JO (1996b). Pathogenesis of mouse hepatitis virus-induced demyelination. J NeuroVirol 2: 361-376.

Iacono KT, Kazi L, Weiss SR (2006). Both spike and background genes contribute to murine coronavirus neurovirulence. J Virol 80: 6834-6843.

Karman J, Ling C, Sandor M, Fabry Z (2004). Initiation of immune responses in brain is promoted by local dendritic cells. J Immunol 173: 2353-2361.

Kazi L, Lissenberg A, Watson R, de Groot RJ, Weiss SR (2005). Expression of hemagglutinin esterase protein from recombinant mouse hepatitis virus enhances neurovirulence. J Virol 79: 15064-15073.

Knobler RL, Haspel MV, Oldstone MB (1981). Mouse hepatitis virus type 4 (JHM strains) induced fatal central nervous system disease. I. genetic control and murine 
neuron as the susceptible site of disease. J Exp Med 153: 832-843.

Koetzner CA, Kuo L, Goebel SJ, Dean AB, Parker MM, Masters PS (2010). Accessory protein 5a is a major antagonist of the antiviral action of interferon against murine coronavirus. J Virol 84: 8262-8274.

Krueger DK, Kelly SM, Lewicki DN, Ruffolo R, Gallagher TM (2001). Variations in disparate regions of the murine coronavirus spike protein impact the initiation of membrane fusion. $J$ Virol 75: 2792-2802.

LaMonica N, Banner LR, Morris VL, Lai MMC (1991). Localization of extensive deletions in the structural genes of two neurotropic variants of murine coronavirus JHM. Virology 182: 883-888.

Lampert PW, Sims JK, Kniazeff AJ (1973). Mechanism of demyelination in JHM virus encephalomyelitis. Acta Neurophathol (Berl) 24: 76-85.

Lavi E, Fishman PS, Highkin MK, Weiss SR (1988). Limbic encephalitis after inhalation of a murine coronavirus. Lab Invest 58: 31-36.

Lavi E, Gilden DH, Highkin MK, Weiss SR (1986). The organ tropism of mouse hepatitis virus A59 in mice is dependent on dose and route of inoculation. Lab Anim Sci 36: 130-135.

Lavi E, Gilden DH, Wroblewska Z, Rorke LB, Weiss SR (1984). Experimental demyelination produced by the A59 strain of mouse hepatitis virus. Neurology 34: 597-603.

Lin MT, Hinton DR, Marten NW, Bergmann CC, Stohlman SA (1999). Antibody prevents virus reactivation within the central nervous system. J Immunol 162: 7358-7368.

Lin MT, Stohlman SA, Hinton DR (1997). Mouse hepatitis virus is cleared from the central nervous systems of mice lacking perforin-mediated cytolysis. J Virol 71: 383-391.

Macnamara KC, Bender SJ, Chua MM, Watson R, Weiss SR (2008). Priming of CD8+ T cells during central nervous system infection with a murine coronavirus is straindependent. J Virol 82: 6150-6160.

MacNamara KC, Chua MM, Phillips JJ, Weiss SR (2005). Contributions of the viral genetic background and a single amino acid substitution in an immunodominant CD8+ T-cell epitope to murine coronavirus neurovirulence. J Virol 79: 9108-9118.

Marten NW, Stohlman SA, Bergmann CC (2001). MHV infection of the CNS: mechanisms of immune-mediated control. Viral Immunol 14: 1-18.

Marten NW, Stohlman SA, Zhou J, Bergmann CC (2003). Kinetics of virus-specific CD8+-T-cell expansion and trafficking following central nervous system infection. J Virol 77: 2775-2778.

Matsubara Y, Watanabe R, Taguchi F (1991). Neurovirulence of six different murine coronavirus JHMV variants for rats. Virus Res 20: 45-58.

Matthews AE, Weiss SR, Shlomchik MJ, Hannum LG, Gombold JL, Paterson Y (2001). Antibody is required for clearance of infectious murine hepatitis virus
A59 from the central nervous system, but not the liver. J Immunol 167: 5254-5263.

Miura TA, Travanty EA, Oko L, Bielefeldt-Ohmann H, Weiss SR, Beauchemin N, Holmes KV (2008). The spike glycoprotein of murine coronavirus MHV-JHM mediates receptor-independent infection and spread in the central nervous system of Ceacam1a-/- mice. J Virol 82: 755-763.

Nakagaki K, Taguchi F (2005). Receptor-independent spread of a highly neurotropic murine coronavirus JHMV strain from initially infected microglial cells in mixed neural cultures. J Virol 79: 6102-6110.

Navas S, Weiss SR (2003). Murine coronavirus-induced hepatitis: JHM genetic background eliminates A59 spike-determined hepatotropism. J Virol 77: 4972-4978.

Ontiveros E, Kim TS, Gallagher TM, Perlman S (2003). Enhanced virulence mediated by the murine coronavirus, mouse hepatitis virus strain JHM, is associated with a glycine at residue 310 of the spike glycoprotein. J Virol 77: 10260-10269.

Ontiveros E, Kuo L, Masters PS, Perlman S (2001). Inactivation of expression of gene 4 of mouse hepatitis virus strain JHM does not affect virulence in the murine CNS. Virology 289: 230-238.

Parham D, Tereba A, Talbot PJ, Jackson DP, Morris VL (1986). Analysis of JHM central nervous system infections in rats. Arch Neurol 43: 702-708.

Parra B, Hinton DR, Marten NW, Bergmann CC, Lin MT, Yang CS, Stohlman SA (1999). IFN-gamma is required for viral clearance from central nervous system oligodendroglia. J Immunol 162: 1641-1647.

Parra B, Lin MT, Stohlman SA, Bergmann CC, Atkinson R, Hinton DR (2001). Contributions of Fas-Fas ligand interactions to the pathogenesis of mouse hepatitis virus in the central nervous system. J Virol 74: 2447-2450.

Pasick JM, Kalicharran K, Dales S (1994). Distribution and trafficking of JHM coronavirus structural proteins and virions in primary neurons and the OBL-21 neuronal cell line. J Virol 68: 2915-2928.

Perlman S, Jacobsen G, Afifi A (1989). Spread of a neurotropic murine coronavirus into the CNS via the trigeminal and olfactory nerves. Virology 170: 556-560.

Perlman S, Schelper R, Bolger E, Ries D (1987). Late onset, symptomatic, demyelinating encephalomyelitis in mice infected with MHV-JHM in the presence of maternal antibody. Microb Pathog 2: 185-194.

Perlman S, Sun N, Barnett EM (1995). Spread of MHV-JHM from nasal cavity to white matter of spinal cord. Transneuronal movement and involvement of astrocytes. $A d v$ Exp Med Biol 380: 73-78.

Phillips JJ, Chua MM, Lavi E, Weiss SR (1999). Pathogenesis of chimeric MHV4/MHV-A59 recombinant viruses: the murine coronavirus spike protein is a major determinant of neurovirulence. J Virol 73: 7752-7760.

Phillips JJ, Chua MM, Rall GF, Weiss SR (2002). Murine coronavirus spike glycoprotein mediates degree of viral spread, inflammation, and virus-induced immunopathology in the central nervous system. Virology 301: 109-120. 
Putics A, Filipowicz W, Hall J, Gorbalenya AE, Ziebuhr J (2005). ADP-ribose-1'-monophosphatase: a conserved coronavirus enzyme that is dispensable for viral replication in tissue culture. $J$ Virol 79: 12721-12731.

Putics A, Gorbalenya AE, Ziebuhr J (2006). Identification of protease and ADP-ribose 1 '-monophosphatase activities associated with transmissible gastroenteritis virus nonstructural protein 3. J Gen Virol 87: 651-656.

Ramakrishna C, Bergmann CC, Holmes KV, Stohlman SA (2004). Expression of the mouse hepatitis virus receptor by central nervous system microglia. J Virol 78: 7828-7832.

Rempel JD, Murray SJ, Meisner J, Buchmeier MJ (2004a). Differential regulation of innate and adaptive immune responses in viral encephalitis. Virology 318: 381-392.

Rempel JD, Murray SJ, Meisner J, Buchmeier MJ (2004b). Mouse hepatitis virus neurovirulence: evidence of a linkage between $S$ glycoprotein expression and immunopathology. Virology 318: 45-54.

Roth-Cross JK, Stokes H, Chang G, Chua MM, Thiel V, Weiss SR, Gorbalenya AE, Siddell SG (2009). Organspecific attenuation of murine hepatitis virus strain A59 by replacement of catalytic residues in the putative viral cyclic phosphodiesterase ns2. J Virol 83: 3743-3753.

Schwarz B, Routledge E, Siddell SG (1990). Murine coronavirus nonstructural protein ns2 is not essential for virus replication in transformed cells. J Virol 64: 4784-4791.

Scott EP, Branigan PJ, Del Vecchio AM, Weiss SR (2008). Chemokine expression during mouse hepatitis virusinduced encephalitis: contributions of the spike and background genes. J NeuroVirol 14: 5-16.

Stevenson PG, Hawke S, Sloan DJ, Bangham CR (1997). The immunogenicity of intracerebral virus infection depends on anatomical site. J Virol 71: 145-151.

Stohlman SA, Bergmann CC, Lin MT, Cua DJ, Hinton DR (1998). CTL effector function within the central nervous system requires CD4+ $\mathrm{T}$ cells. $J$ Immunol 160: 2896-2904.

Sun N, Perlman S (1995). Spread of a neurotropic coronavirus to spinal cord white matter via neurons and astrocytes. J Virol 69: 633-641.

Sussman MA, Shubin RA, Kyuwa S, Stohlman SA (1989). T-cell-mediated clearance of mouse hepatitis virus strain JHM from the central nervous system. J Virol 63: 3051-3061.

Sutherland RM, Chua MM, Lavi E, Weiss SR, Paterson Y (1997). CD4+ and CD8+ T cells are not major effectors of mouse hepatitis virus A59-induced demyelinating disease. J NeuroVirol 3: 225-228.

Taguchi F, Matsuyama S, Saeki K (1999). Difference in Bgp-independent fusion activity among mouse hepatitis viruses. Arch Virol 144: 2041-2049.

Taguchi F, Siddell SG, Wege H, ter Meulen V (1985). Characterization of a variant virus selected in rat brains after infection by a coronavirus mouse hepatitis virus JHM. J Virol 54: 429-435.

Tsai JC, Zelus BD, Holmes KV, Weiss SR (2003). The $\mathrm{N}$-terminal domain of the murine coronavirus spike glycoprotein determines the CEACAM1 receptor specificity of the virus strain. J Virol 77: 841-850.

Wang FI, Hinton DR, Gilmore W, Trousdale MD, Fleming JO (1992). Sequential infection of glial cells by the murine hepatitis virus JHM strain (MHV-4) leads to a characteristic distribution of demyelination. $L a b$ Invest 66: 744-754.

Weiner LP (1973). Pathogenesis of demyelination induced by a mouse hepatitis. Arch Neurol 28: 298-303.

Weiss SR, Navas-Martin S (2005). Coronavirus pathogenesis and the emerging pathogen severe acute respiratory syndrome coronavirus. Microbiol Mol Biol Rev 69: 635-664.

Yokomori K, Asanaka M, Stohlman SA, Makino S, Shubin RA, Gilmore W, Weiner LP, Wang FI, Lai MM (1995). Neuropathogenicity of mouse hepatitis virus JHM isolates differing in hemagglutinin-esterase protein expression. J NeuroVirol 1: 330-339.

Yokomori K, Baker SC, Stohlman SA, Lai MM (1992). Hemagglutinin-esterase-specific monoclonal antibodies alter the neuropathogenicity of mouse hepatitis virus. J Virol 66: 2865-2874.

Yokomori K, Lai MM (1991). Mouse hepatitis virus S RNA sequence reveals that nonstructural proteins ns4 and ns5a are not essential for murine coronavirus replication. J Virol 65: 5605-5608.

Yokomori K, Stohlman SA, Lai MM (1993). The detection and characterization of multiple hemagglutinin-esterase (HE)-defective viruses in the mouse brain during subacute demyelination induced by mouse hepatitis virus. Virology 192: 170-178.

Zhou J, Stohlman SA, Atkinson R, Hinton DR, Marten NW (2002). Matrix metalloproteinase expression correlates with virulence following neurotropic mouse hepatitis virus infection. J Virol 76: 7374-7384.

Zhou J, Stohlman SA, Hinton DR, Marten NW (2003). Neutrophils promote mononuclear cell infiltration during viral-induced encephalitis. I Immunol 170: 3331-3336. 